\title{
Xp21 microdeletion syndrome
}

INSERM

\section{Source}

INSERM. (1999). Orphanet: an online rare disease and orphan drug data base. Xp21 microdeletion syndrome. ORPHA:261476

Xp21 microdeletion syndrome is a rare chromosomal anomaly characterized by complex glycerol kinase deficiency, congenital adrenal hypoplasia, intellectual disability and/or Duchenne muscular dystrophy that usually affect males. The clinical features depend on the deletion size and the number and type of involved genes. 